\title{
FORMULATION AND DISSOLUTION PROFILE STUDY OF TRANSFERSOME-LOADED MICROSPHERES FROM GREEN TEA LEAF EXTRACT
}

\author{
EFFIONORA ANWAR*, PUTRI AMALIA HANDAYANI \\ Department of Pharmaceutical Technology, Faculty of Pharmacy, Universitas Indonesia, Depok, 16424, Indonesia. \\ Email: effionora.anwar@farmasi.ui.ac.id
}

Received: 01 June 2018, Revised and Accepted: 19 November 2018

\section{ABSTRACT}

Objective: The aim of this study was to prepare transfersome-loaded microspheres which had good characteristics and physicochemical stability to increase bioavailability of the polyphenol component of green tea leaf extract in the body.

Methods: Transfersomes were prepared using a thin-layer hydration method. Green tea leaf extract transfersomes were formulated in the ratio of 95:5, 90:10, and 85:15 based on their phospholipid and Span 80 content.

Results: The most successful formula produced transfersomes of a spherical shape, 78.75 nm in size with a polydispersity index of 0.187 , zeta potential of $-37.5 \mathrm{mV}$, and entrapment efficiency of $47.96 \pm 5.81 \%$. Subsequently, the transfersome was loaded into a microsphere using the spray-dry method. The microspheres had a non-spherical, wrinkled shape, their size was $2058.44 \mathrm{~nm}$, their polydispersity index was 0.545 , their entrapment efficiency was $59.27 \pm 0.59 \%$, their moisture content was $5.21 \%$, and their swelling index was $289.36 \%$ after 4 h. The total cumulative amount of Epigallocatechin-3-gallate after a dissolution test was $69.15 \pm 7.66 \%$.

Conclusion: The physicochemical stability of transfersome-loaded microspheres was not significantly different from that of transfersome powder.

Keywords: Dissolution profile study, Epigallocatechin gallate, Green tea leaf extract, Microsphere, Transfersome.

(C) 2018 The Authors. Published by Innovare Academic Sciences Pvt Ltd. This is an open access article under the CC BY license (http://creativecommons. org/licenses/by/4. 0/) DOI: http://dx.doi.org/10.22159/ijap.2018.v10s1.47

\section{INTRODUCTION}

Green tea is the most popular drink in Indonesian society and has become one of the country's largest export commodities. Based on data compiled by the Food and Agriculture Organization of the United Nations, Indonesia's tea production was 152,700 tons $/ \mathrm{m}^{2}$ in 2013 [1]. Green tea leaf extract contains several major compounds, such as carbohydrates, proteins, and methyl xanthin. However, the largest and most interesting components are polyphenols, particularly catechins, such as epicatechin (EC), EC error (ECG), epigallocatechin (EGC), and EGC error (EGCG) [2]. During manufacturing green tea, the content is maintained in such condition to prevent oxidation.

Regular consumption of green tea has been proven to have many health benefits. Green tea leaves have potential anti-proliferative activity and synergistic antibacterial activity [3]. Epidemiological data suggest that green tea reduces a person's risk of chronic and degenerative diseases, such as some cancers, cardiovascular disease, neurodegenerative diseases, diabetes, obesity, and Alzheimer's disease. In addition, green tea also has antioxidant, anticarcinogenic, and anti-inflammatory properties [4]. Numerous studies have shown the beneficial effects on the regular intake of green tea in maintaining oral health [5]. However, many people dislike green tea due to its bitterness, which is caused by catechins. The catechins undergo degradation or epimerization due to the effects of temperature, $\mathrm{pH}$, light, oxygen, and enzymatic reactions, all of which lead to decreased catechin efficacy in giving health benefits. Therefore, to achieve maximum benefits from green tea, techniques are required for preventing decomposition during tea production, storage, and distribution process [6] In general, active constituents present in plants or phytoconstituents are polar or water soluble, whereas the biological membrane that they must pass is rich in lipids [7]. In $213.6 \pm 2.3 \mathrm{mg}$ of EGCG consumption a test shows it produces a maximum concentration of $80 \pm 10 \mathrm{nmol} / \mathrm{L}$ [8].
To increase bioavailability of the polyphenol component in the body, green tea leaf extract can be combined with transfersome technology. Transfersomes were first introduced by Gregor Cevc in 1991 and were patented by the German company IDEA AG. Transfersomes can entrap active substances in the form of chemicals and natural materials [9]. Transfersomes are so elastic that they can penetrate the cell membrane, not only due to their amphetical nature but also because they can change shape [10]. Some studies indicate that an appropriate combination of different carrier systems can mask deficiencies of other carriers. One of the deficiencies of transfersomes is that they are susceptible to oxidative degradation. Therefore, ready-made transfersomes need to be protected using a microsphere system. Microspheres are a microparticle technology in which active substances are evenly distributed within the matrix system. The purpose of forming a microsphere system outside the transfersome is that the microspheres can protect the transfersome during storage [11].

In our previous investigation [12], sodium alginate mucoadhesive microspheres of maraviroc controlled the drug release for $8 \mathrm{hrs}$. To prolong the maraviroc release, improve mucoadhesion, bioavailability and to reduce dosing frequency, a suitable formulation was required with a controlled rate to treat anti-HIV patients. In the present study, mucoadhesive microspheres were developed using a hydrophilic polymer, Hydroxypropyl methylcellulose (HPMC K4M, K15M, and $\mathrm{K} 100$ ), and pectin in combination with sodium alginate.

\section{MATERIALS AND METHODS}

\section{Determination of the EGCG content of extracts}

The EGCG content was determined using high-performance liquid chromatography (HPLC) system consisting of a Shimadzu HPLC model LC-20AT, UV-Vis Detector SPD-20A, Column Shimadzu C18 (250×4.6 mm), Lab Solution data processor, and Prolink Integrator. Reverse-phase chromatography was used, and an isocratic motion 
elution system with a $0.05 \%$ acetic acid action phase, acetonitrile $(87: 13 \mathrm{v} / \mathrm{v})$, a flow rate of $1.0 \mathrm{~mL} / \mathrm{min}$, and a wavelength of $280 \mathrm{~nm}$ was used. A system suitability test was performed first by injecting the EGCG standard into the system HPLC 6 times at a concentration of $500 \mu \mathrm{g} / \mathrm{mL}$. The parameters observed are coefficient values of the variation in width and retention time obtained from six injections. Calibration curves were then produced for EGCG concentrations of 25, $30,35,40,45$, and $50 \mu \mathrm{g} / \mathrm{mL}$. Each concentration was injected into the HPLC system, and its width was noted. A calibration curve was produced using linear regression of the concentration, and width was obtained. Finally, $100 \mathrm{mg}$ of the sample was extracted in a $25.0 \mathrm{~mL}$ mobile phase. Next, the analyte solution was filtered using a $0.45 \mu \mathrm{m}$ microfilter and diluted 100 times with the mobile phase. Then, $20 \mu \mathrm{L}$ of the filtrate was injected into the HPLC system. The experiment was repeated 3 times. The EGCG content was calculated based on a standard curve [12], and the EGCG concentration was calculated using the calibration curve equation $(y=a+b x)$ where $x$, measurable concentration and $y$, height of area. The EGCG content in the sample was calculated by dividing measured concentration with spotted concentration then times $100 \%$.

\section{Antioxidant activity test: The 2,2-diphenyl-1-picrylhydrazyl (DPPH) method}

Antioxidant activity of the green tea leaf extract was determined and compared with that of DPPH. This test was based on the determination of the damping activity of green tea leaf extract samples to obtain an $\mathrm{IC}_{50}$ value of the extract [13]. First, the antioxidant activity of $100 \mathrm{~mL} / \mathrm{mL}$ DPPH solution was determined by determining the maximum wavelength on mixing $1 \mathrm{~mL}$ DPPH solution with $3 \mathrm{~mL}$ of methanol. Blank solution used was ascorbic acid at six concentrations $(2,3,4,6,8$, and $10 \mu \mathrm{g} / \mathrm{mL})$, whereas the green tea leaf extract solution was prepared at concentrations of $1,2,3,4,5$, and $6 \mu \mathrm{g} / \mathrm{mL}$. Next, the test solution was prepared by dissolving $1 \mathrm{~mL}$ of each sample solution with $1 \mathrm{~mL}$ of $100 \mu \mathrm{g} / \mathrm{mL}$ DPPH solution and $2 \mathrm{~mL}$ methanol. Ascorbic acid solutions at various concentrations were subjected to the same treatment as the test solution. Each mixture was homogenized and incubated at room temperature $\left(25-30^{\circ} \mathrm{C}\right)$ for $30 \mathrm{~min}$. Then, antioxidant activity was tested using UV-Vis spectrophotometry. Absorption was measured at a wavelength of $400-800 \mathrm{~nm}$ with an optimum wavelength of $514 \mathrm{~nm}$. Absorption data obtained were fed into the following inhibition percentage by dividing (control absorbance - sample absorbance) with control absorbance then times 100 .

\section{Transfersome formulation with green tea leaf extract}

In the present study, $100 \mathrm{~mL}$ of each of three variations of transfersome formula (F1, F2, and F3) were produced. The formulations may be distinguished based on their Lipoid P30 and Span 80 contents (details of which are shown in Table 1).

Transfersomes were prepared according to the method used by Rajan and Vasudevan [14], with various modifications. The method comprises two stages, namely, the thin-layer process and the hydration process. The thin-layer process was conducted by dissolving Lipoid P30 and Span 80 in a chlorinated organic solvent. The solution was evaporated at $39^{\circ} \mathrm{C}$ in a rotary evaporator at $50 \mathrm{rpm}$, gradually increasing to $150 \mathrm{rpm}$ until the organic solvent evaporated and formed a thin, evenly spaced layer on the round flask wall. Once formed, nitrogen gas was added and the flask was allowed to stand in the refrigerator for $24 \mathrm{~h}$.

Table 1: Transfersome formulations

\begin{tabular}{llll}
\hline Substance & \multicolumn{3}{l}{ Concentration (b/v) } \\
\cline { 2 - 4 } & F1 & F2 & F3 \\
\hline EGCG & 3 & 3 & 3 \\
Lipoid P30 & 9.5 & 9.0 & 8.5 \\
Span 80 & 0.5 & 1.0 & 1.5 \\
Phosphate buffer (pH 5.5) & ad 100 & ad 100 & ad 100 \\
\hline
\end{tabular}

EGCG: Epigallocatechin-3-gallate
In the hydration process, phosphate buffer ( $\mathrm{pH}$ 5.5) was used to dissolve the green tea leaf extract, and the solution was put into the round flask with the thin layer of lipid produced during the first stage. Glass beads were used to hydrate all layers and promote homogenous transfersome suspension. The hydration process was conducted in a rotary evaporator at a rate of $150 \mathrm{rpm}$ at $39^{\circ} \mathrm{C}$ without a vacuum. After completion, the transfersome suspension was subjected to ultrasonication for $10 \mathrm{~min}$ at 25 amplitude and then centrifuged to separate the extracts absorbed or not absorbed by the transfersome.

\section{Characterization of transfersomes}

Characterization of the transfersome included determination of the particle size, measurement of the polydispersity index and zeta potential using a particle size analyzer, analysis of the transfersome morphology using a transmission electron microscope (TEM), and calculation of the efficiency of induction by dividing (EGCG total - EGCG supernatant) with EGCG total then times 100.

Transfersome microsphere formulation with green tea leaf extract A breakdown of the composition of the transfersome microsphere formulation is given in Table 2 .

Gum arabic was dissolved in Aqua Dest at a ratio of $1: 2.7$ at $60-80^{\circ} \mathrm{C}$, whereas maltodextrin was dissolved in Aqua Dest at $40-60^{\circ} \mathrm{C}$ for $1 \mathrm{~h}$ using a magnetic stirrer. The mixture of maltodextrin and gum arabic with the transfersome suspension was homogenized using a homogenizer at a rate of $1500 \mathrm{rpm}$. Then, the dispersion was dried in a spray dryer with an inlet temperature of $125^{\circ} \mathrm{C}$ and an outlet temperature of $60^{\circ} \mathrm{C}$. The flow rate was $5 \mathrm{~mL} / \mathrm{min}$. The readymade microspheres were stored in a shelter. Then, the ready-made microsphere powder was immediately placed inside a sealed container and inserted into a desiccator.

\section{Characterization of transfersome microspheres}

Characterization of the transfersome included determination of the particle size and measurement of the polydispersity index using a particle size analyzer, morphology analysis of transfersomes using a scanning electron microscope (SEM), measurement of induction efficiency using an indirect method, and measurement of moisture and an index test for four microspheres using the following formula:

$$
\% \text { Expand }=\frac{\text { Final weight }- \text { initial weight }}{\text { Initial weight }} \times 100 \%
$$

\section{Transfersome microsphere dissolution test}

This test was conducted in $100 \mathrm{~mL}$ phosphate buffer medium (pH 7.4) using a tea bag and performed on a hotplate at a temperature of $37^{\circ} \mathrm{C}$ and a magnetic stirrer at $100 \mathrm{rpm}$. Samples were taken at 0, 15, 30, 45, $60,120,180$, and $240 \mathrm{~min}$; then, the concentration levels were tested by HPLC. Tests were performed with microspheric compounds and extracts as well as transfersome and extracts [15]. At the $45^{\text {th }} \mathrm{min}$, transfersome morphology was analyzed by TEM to confirm the presence of transfersomes inside the microspheres.

Linear regression: $\mathrm{y}=\mathrm{a}+\mathrm{bx}$

$$
\mathrm{W}_{10}(\mathrm{mg})=\frac{\mathrm{Y}_{10}-\mathrm{a} \times \mathrm{Fp} \times \mathrm{M}}{\mathrm{b} \times 1000}
$$

Table 2: Microsphere formulation

\begin{tabular}{llll}
\hline Substance & \multicolumn{3}{l}{ Concentration $(\mathbf{b} / \mathbf{v})$} \\
\cline { 2 - 4 } & MT & ST & ME \\
\hline EGCG & 3 & 3 & 3 \\
Maltodextrin & 7.20 & - & 7.20 \\
Gum arabic & 4.80 & - & 4.80 \\
\hline
\end{tabular}

MT: Transfersome microsphere, ST: Transfersome substance, ME: Microsphere extract 


$$
\begin{aligned}
& W_{15}(\mathrm{mg})=\frac{\mathrm{Y}_{15}-\mathrm{a} \times \mathrm{Fp} \times \mathrm{M}}{\mathrm{b} \times 1000}+\frac{\mathrm{Y}_{10}-\mathrm{a} \times \mathrm{Fp} \times \mathrm{S}}{\mathrm{b} \times 1000} \\
& \mathrm{~W}_{30}(\mathrm{mg})=\frac{\mathrm{Y}_{30}-\mathrm{a} \times \mathrm{Fp} \times \mathrm{M}}{\mathrm{b} \times 1000}+\frac{\mathrm{Y}_{15}-\mathrm{a} \times \mathrm{Fp} \times \mathrm{S}}{\mathrm{b} \times 1000}+\frac{\mathrm{Y}_{10}-\mathrm{a} \times \mathrm{Fp} \times \mathrm{S}}{\mathrm{b} \times 1000}
\end{aligned}
$$

$\mathrm{W}$, cumulative weight of EGCG described at $\mathrm{n}$ min; Y, width at $\mathrm{n}$ min; $\mathrm{a}$, $\mathrm{y}$-intercept; Fp, dilution factor; $\mathrm{M}$, volume of medium used; b, gradient

\section{Stability test}

This test was performed by storing $5 \mathrm{~g}$ of transfersome microspheres in a brown vial for 12 weeks at $4^{\circ} \mathrm{C}, 28^{\circ} \mathrm{C}$, and $40^{\circ} \mathrm{C}$. Every 2 weeks, $100 \mathrm{mg}$ of the sample was taken and tested for antioxidant activity using DPPH. Transfersome samples of green tea leaf extract dried using the spray drying technique were used as controls [16].

\section{RESULTS AND DISCUSSION}

\section{Results}

Determination of EGCG levels in green tea leaf extract

Based on six standard injections of $300 \mu \mathrm{g} / \mathrm{mL}$ into the HPLC system, the retention time was between 17 and $18 \mathrm{~min}$. Based on the system suitability test, the percentage coefficient of variation from the peak was $0.75 \%$, whereas based on the retention time, it was $1.12 \%$. The linear regression equation obtained was $y=30280 x-400552$, with $r=0.9939$. Subsequently, EGCG level on a sample was determined using approximately $40 \mu \mathrm{g} / \mathrm{mL}$ green tea leaf extract. The peak of the obtained chromatogram is included as y in the linear regression equation, which gives an average EGCG level of $53.80 \pm 1.19 \%$.

\section{Antioxidant activity of green tea leaf extract}

The $\mathrm{IC}_{50}$ value of the green tea leaf extract was $1.33 \mu \mathrm{g} / \mathrm{mL}$, whereas that of ascorbic acid was $2.60 \mu \mathrm{g} / \mathrm{mL}$

\section{Characterization of transfersomes}

Transfersome morphology was examined using TEM. This indicated that the transfersomes were spherical in shape and that the extract was surrounded by a phospholipid layer with a surfactant as shown in Fig.1.
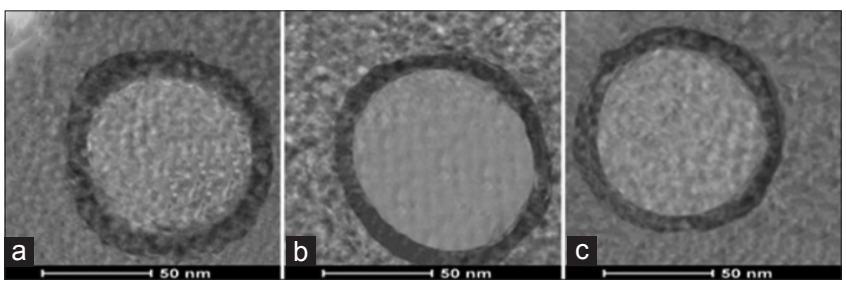

Fig. 1: Transfersome morphology (a) F1, (b) F2, and (c) F3

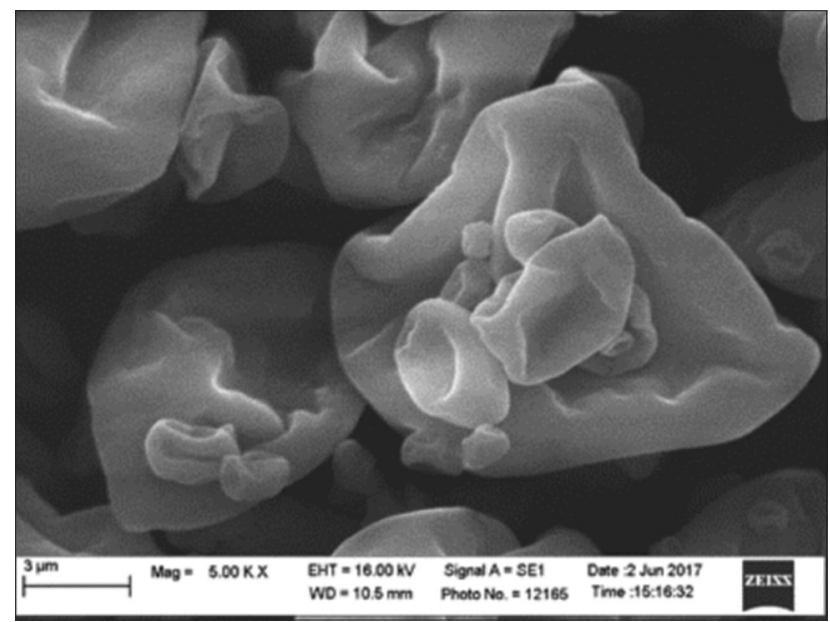

Fig. 2: Microsphere morphology
The formulation selected for microspherical transfersomes was F1, as it had the smallest particle size, a polydispersity index $\leq 0.5$, zeta potential $\geq \pm 30 \mathrm{mV}$, and the largest absorption efficiency.

\section{Characterization of transfersome microspheres}

SEM microphotographs showed that the microspheres were of varying sizes, non-spherical in shape, and tended to crease as shown in Fig. 2. The results of the particle size distribution test on transfersome microspheres showed that the average powder had particles of $2058.44 \mathrm{~nm}$ in size with a polydispersity index of 0.545 . Results of the efficiency analysis showed that the average adsorption efficiency was $59.27 \pm 0.59 \%$. In the $1^{\text {st }}$ week of testing, the water content of the transfersome microsphere formulation was $5.21 \%$, whereas that in the transfersome powder was $4.41 \%$ (Fig. 3).

Transfersome morphology in microspheres after dissolution The morphology of green tea leaf extract transfersomes that had been inserted into microspheres was examined after $45 \mathrm{~min}$ of samples dissolution. The results are shown in Fig. 4.

\section{Transfersome microsphere stability test}

The microsphere stability test was performed for 12 weeks at three temperatures: $4^{\circ} \mathrm{C}, 28^{\circ} \mathrm{C}$, and $40^{\circ} \mathrm{C}$. The reference parameters were transfersome microsphere antioxidant activity and the green tea leaf transfersome powder. Changes in $\mathrm{IC}_{50}$ occurring at each week were calculated and statistically analyzed using t-tests between two variables based on the mean values of each variable. The test results showed that there was no significant difference between transfersomes and transfersome powder at any temperature $(\mathrm{p}>0.05)$ as shown in Table 3.

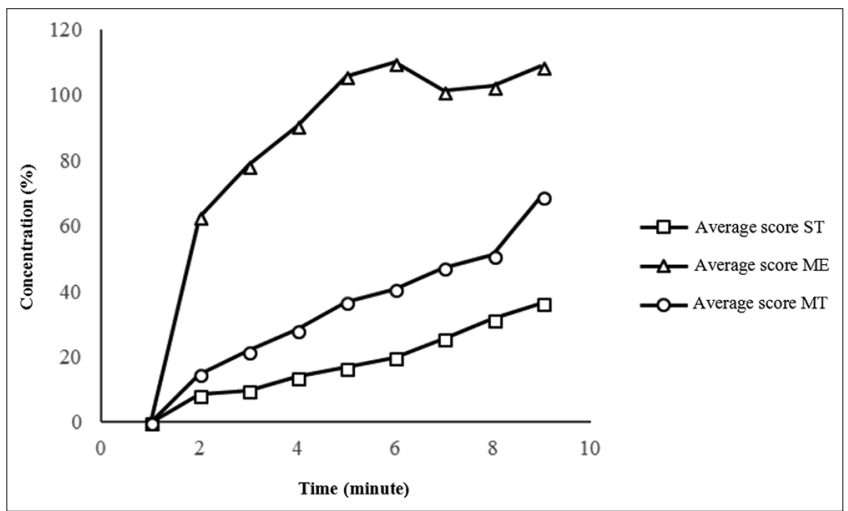

Fig. 3: Epigallocatechin-3-gallate release rate curve

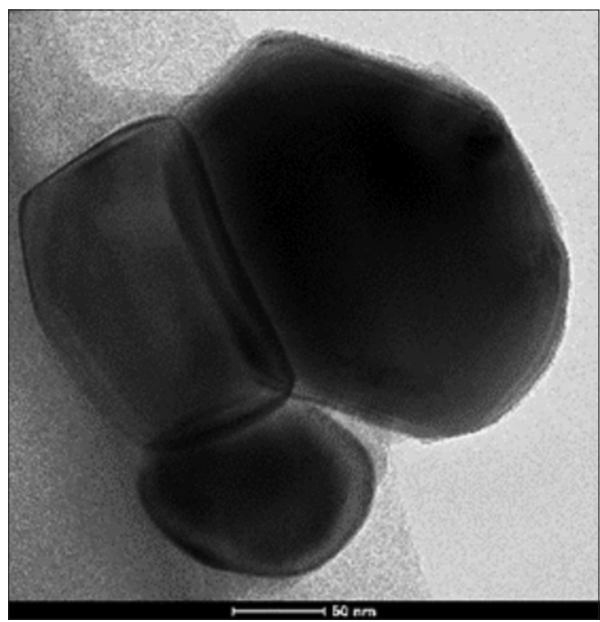

Fig. 4: Transfersome morphology in the microspheres in the dissolution sample 


\section{Dissolution test}

This test was performed on transfersome microspheres, transfersome powder, and extract microspheres for $4 \mathrm{~h}$. After three tests on transfersome microspheres, the last cumulative percentage of EGCG at the $4^{\text {th }} \mathrm{h}$ was $69.15 \pm 7.66 \%$, whereas that of the transfersome powder was $36.56 \pm 0.99 \%$ and that of the microsphere extract was $108.78 \pm 1.38 \%$ as shown in Fig. 3 .

\section{Determination of EGCG levels in green tea leaf extract}

HPLC was chosen for determining EGCG levels due to its high sensitivity and selectivity; the HPLC method is viable even with low concentrations of samples and can separate EGCG from other components present in the extract [17].

The phase of motion used in this study was based on that used by Fangueiro et al., with some modifications [12] Fangueiro et al. [12] used $0.1 \%$ acetic acid, but because the $\mathrm{pH}$ of the mobile phase was still too low, in this study, $0.05 \%$ acetic acid and acetonitrile at a ratio of $87: 13$, with a $\mathrm{pH}$ between 3.5 and 4.0 , was used. The $\mathrm{pH}$ was adjusted to a $\mathrm{pH}$ at which EGCG was stable. Before the determination of the level, the system suitability test was performed. The method used has been validated previously, but because a different test system was be used, six standard injections of $300 \mu \mathrm{g} / \mathrm{mL}$ were introduced into the HPLC system [18]. The retention time differed between the present study and the method already validated; in the former, the retention time was between 17 and $18 \mathrm{~min}$, whereas in the latter, the retention time was between 12 and $13 \mathrm{~min}$. This is because the previous study used a column with a length of $10 \mathrm{~cm}$, whereas, in this study, we used a column with a length of $25 \mathrm{~cm}$ [12].

After the system suitability test, the percentage coefficient of variation from the peak was $0.75 \%$, whereas, from the retention time, it was $1.12 \%$. From these results, it is clear that this method may be used for EGCG assay analysis. The correlation coefficient was acceptable because the value of $\mathrm{r}$ was close to 1

\section{Green tea leaf extract antioxidant activity test}

The test was performed using DPPH. The method is based on the principle of colorimetry, in which the color of the DPPH solution in methanol will change from purple to yellow after being given antioxidants. These color changes occur due to the reduction of $\mathrm{DPPH}^{\cdot}$ to $\mathrm{DPPH}_{2}$ by hydrogen elements derived from antioxidant compounds [19].

The value of $\mathrm{IC}_{50}$ obtained using the green tea leaf extract was $1.33 \mu \mathrm{g} / \mathrm{mL}$, whereas that obtained using ascorbic acid was $2.60 \mu \mathrm{g} / \mathrm{mL}$. These results indicate that green tea leaf extract exhibits stronger antioxidant activity than ordinary ascorbic acid. This is due to the presence of other chemical substances in the extract that can also function as antioxidants, such as catechins other than EGCG and other flavonoid compounds [20].

Table 3: Mean changes in IC50 of microspheres and transfersome powders at each week

\begin{tabular}{|c|c|c|c|}
\hline \multirow[t]{2}{*}{ Temperature $\left({ }^{\circ} \mathrm{C}\right)$} & \multicolumn{2}{|c|}{ Mean IC50 changes per week } & \multirow[t]{2}{*}{$p$ value } \\
\hline & MT $(\mu \mathrm{g} / \mathrm{mL})$ & ST $(\mu \mathrm{g} / \mathrm{mL})$ & \\
\hline 4 & 0.137 & 0.127 & 0.46 \\
\hline 28 & 0.049 & 0.053 & 0.44 \\
\hline 40 & 0.060 & 0.082 & 0.33 \\
\hline
\end{tabular}

\section{Characterization of green tea leaf extract transfersomes}

As can be seen from data in Table 4, F1 produced transfersomes of $78.75 \mathrm{~nm}$, whereas F2 and F3 produced transfersomes of 101.70 and $91.39 \mathrm{~nm}$. The lower the HLB value of the surfactant used, the smaller the particle size produced [21]. In addition, the greater the amount of surfactant used, the smaller the size will be because more surfactant produces more micelles than vesicles and the latter tend to be larger [22]. Compared with the results obtained by this study, there is a discrepancy in F1. Thus, in the efficiency analysis of absorption, the formula with the highest absorption efficiency was F1, whereas the second is F2 followed by F3. High F1 absorption efficiency is due to F1 having a higher amount of phospholipids than other formulas; therefore, there is more EGCG protected within it. Although in a study conducted by Jain et al. with the same three formulas used in this study, the efficiency of adsorption was above $90 \%$ [22] due to different types of phosphatidylcholine and active ingredients used and the results of the utilization efficiency were also different. In addition, the amount of surfactant contributes to the efficiency of adsorption. The greater the amount of surfactant, the greater the efficiency of adsorption. This is because there will be vesicles and micelles in the suspension; due to their rigidity and small size between the mixture of micelles, the efficiency of their adsorption will be reduced [21]. The selected formula for transfersome microspheres with green tea leaf extract was F1 because it resulted in the smallest particle size and efficiency the greatest impulse.

\section{Characterization of transfersome microspheres}

The results of the particle size distribution test on transfersome microsphere formulation of green tea leaf extract showed that the average powder was $2058.44 \mathrm{~nm}$ in size with a polydispersity index of 0.545 . A polydispersity index $>0.5$ indicates that the particles are heterogeneous, and the volume-based distribution data are more appropriate to list [23]. In the $1^{\text {st }}$ week of the test, a water content value of $5.21 \%$ was recorded in the transfersome microsphere, whereas that in the transfersome powder was $4.41 \%$. This shows that the presence of maltodextrin and gum arabic tends to attract water [6]. The index test shows that the transfersome microsphere expands up to $289.36 \%$ after $4 \mathrm{~h}$.

\section{Dissolution test}

After three tests on transfersome microspheres, the last cumulative percentage of EGCG at the $4^{\text {th }} \mathrm{h}$ was $69.15 \pm 7.66 \%$, whereas that of the transfersome powder was $36.56 \pm 0.99 \%$ and that of microsphere extract was $108.78 \pm 1.38 \%$. From these results, it can be seen that maltodextrin and gum arabic can accelerate the dissolution rate based on the nature of each hydrophilic polymer [6]. The existence of the transfersome inhibits EGCG expenditure from its matrix because of its depot-like characteristic [22]. Based on the results of the expanding index in the present study, it can be concluded that preparations with large expanded indices have slower dissolution profiles.

\section{Transfersome morphology in microspheres after dissolution} The morphology of green tea leaf extract transfersomes that had been inserted into microspheres was examined after dissolution for $45 \mathrm{~min}$. The sample at the $45^{\text {th }}$ min was chosen because it was estimated that at that minute, the microsphere wall would begin to collapse and the transfersome could be seen again. The purpose of this test was to prove that the transfersome was still in its original form despite having been stirred at high speed and dried using a dry spray method. The

Table 4: Summary of results of the characterization of EGCG transfersomes

\begin{tabular}{llll}
\hline Formula & F1 & F2 & F3 \\
\hline Vesicle morphology & Spherical & Spherical & Spherical \\
Particle size (nm) & 78.75 & 101.70 & 91.39 \\
Polydispersity index & 0.187 & 0.331 & 0.293 \\
Potential zeta (mV) & -37.5 & -55.3 & -52.1 \\
Efficiency of adsorption (\%) & $47.96 \pm 5.81$ & $38.97 \pm 2.08$ & $31.53 \pm 7.50$ \\
\hline
\end{tabular}


transfersome remained inside the microsphere after examination using a TEM (Fig. 4).

\section{Transfersome microsphere stability test}

The microsphere stability test was performed for 12 weeks at three temperatures: $4^{\circ} \mathrm{C}, 28^{\circ} \mathrm{C}$, and $40^{\circ} \mathrm{C}$. There was no significant difference between transfersome and transfersome powder at any temperature $(p>0.05)$. However, the microsphere at $28^{\circ} \mathrm{C}$ had the lowest average value of change compared with those stored at other temperatures. From these data, it can be seen that it is best to store microspheres at room temperature. This is supported by the results of the water content test obtained after 1.5 months of storage, indicating that when stored at $4^{\circ} \mathrm{C}$, the water content of the microspheres increases due to an increase in the absorption of moisture by the microsphere, which causes a decrease instability [6,24]. Similarly, in transfersome powder, the smallest $\mathrm{IC}_{50}$ changes occur at $28^{\circ} \mathrm{C}$. However, transfersome powders have an average value of $\mathrm{IC}_{50}$ changes that are smaller than that of transfersome microspheres, although the difference is not significant.

\section{CONCLUSION}

The characterization results of the three green tea leaf transfersome formulations showed that the first formula had the best characteristics. Once transfersomes were prepared, the microsphere formula had a faster dissolution rate than the transfersome powder. However, transfersome microspheres and transfersome powders do not have significant differences with respect to stability; both substances may be stored at room temperature.

\section{CONFLICTS OF INTEREST}

Authors declare no conflicts of interest.

\section{REFERENCES}

1. Chang K. World Tea Production and Trade: Current and Future Development. Rome, Italy: Food and Agriculture Organization of the United Nations; 2015.

2. Graham HN. Green tea composition, consumption, and polyphenol chemistry. Prev Med 1992;21:334-50.

3. Anand J, Gautam P, Rai N. Comparative study of antibacterial and anti-proliferative potential of green tea from different geographical locations in India. Asian J Pharm Clin Res 2015;8:253-8.

4. Coppock R, Dziwenka M. Green Tea Extract. Nutraceuticals. London: Elsevier; 2016. p. 633-52.

5. Mohan M, Jeevanandan G, Mithun RS. The role of green tea in oral health-a review. Asian J Pharm Clin Res 2018;11:1-3.

6. Zokti JA, Baharin BS, Mohammed AS, Abas F. Green tea leaves extract: Microencapsulation, physicochemical and storage stability study. Molecules 2016;21:1-24.
7. Saraf AS. Applications of novel drug delivery system for herbal formulations. Fitoterapia 2010;81:680-9.

8. Henning SM, Niu Y, Lee NH, Thames GD, Minutti RR, Wang H, et al. Bioavailability and antioxidant activity of tea flavanols after consumption of green tea, black tea, or a green tea extract supplement. Am J Clin Nutr 2004;80:1558-64.

9. Anwar E, Utami TD, Ramadon D. Transfersomal gel containing green tea (Camellia sinensis L. Kuntze) leaves extract: Increasing in vitro penetration. Asian J Pharm Clin Res 2017;10:294-8.

10. Shilakari G, Singh D, Asthana A. Novel vesicular carriers for topical drug delivery and their application's. Int J Pharm Sci Rev Res 2013;21:77-86

11. Zhang J, Tang Q, Xu X, Li N. Development and evaluation of a novel phytosome-loaded chitosan microsphere system for curcumin delivery. Int J Pharm 2013;448:168-74.

12. Fangueiro JF, Parra A, Silva AM, Egea MA, Souto EB, Garcia ML, et al. Validation of a high performance liquid chromatography method for the stabilization of epigallocatechin gallate. Int J Pharm 2014;475:181-90.

13. Hanani E, Munim A, Sekarini R. Identification of antioxidant compounds in Callyspongia sp from Seribu Island. Majalah llmu Kefarmasian 2005;2:127-33.

14. Rajan R, Vasudevan DT. Effect of permeation enhancers on the penetration mechanism of transfersomal gel of ketoconazole. J Adv Pharm Technol Res 2012;3:112-6.

15. Rocha S, Generalov R, Pereira Mdo C, Peres I, Juzenas P, Coelho MA, et al. Epigallocatechin gallate-loaded polysaccharide nanoparticles for prostate cancer chemoprevention. Nanomedicine (Lond) 2011;6:79-87.

16. Yu F, Li Y, Chen Q, He Y, Wang H, Yang L, et al. Monodisperse microparticles loaded with the self-assembled berberine-phospholipid complex-based phytosomes for improving oral bioavailability and enhancing hypoglycemic efficiency. Eur $\mathrm{J}$ Pharm Biopharm 2016;103:136-48.

17. Harmita S. Physicochemistry. Depok: Department of Pharmacy, Universitas Indonesia; 2006

18. Dolan JW. System suitability. LCGC Eur 2004;17:1-4.

19. Mishra K, Ojha H, Chaudhury NK. Estimation of antiradical properties of antioxidants using DPPH assay: A critical review and results. Food Chem 2012;130:1036-43.

20. Harbowy ME, Balentine DA, Davies AP, Cai Y. Tea chemistry. Crit Rev Plant Sci 1997;16:415-80.

21. El Zaafarany GM, Awad GA, Holayel SM, Mortada ND. Role of edge activators and surface charge in developing ultradeformable vesicles with enhanced skin delivery. Int J Pharm 2010;397:164-72.

22. Jain S, Jain P, Umamaheshwari RB, Jain NK. Transfersomes-a novel vesicular carrier for enhanced transdermal delivery: development, characterization, and performance evaluation. Drug Dev Ind Pharm 2003;29:1013-26.

23. Malvern Instruments, Ltd. Zetasizer Nano: User Manual. Worcestershire, United Kingdom: Malvern Instruments, Ltd.; 2013.

24. Arizka AA, Daryatmo J. Changes in moisture and tea water content during storage at different temperatures and packaging. Apl Teknol Pangan J 2015;4:124-9. 